\title{
Medicinal and therapeutic potential of withanolides from Withania somnifera against COVID-19
}

\author{
Manish Dhawan ${ }^{1,2 *}$, Manisha Parmar ${ }^{3}$, Khan Sharun $^{4}$, Ruchi Tiwari ${ }^{5}$, Muhammad Bilal ${ }^{6}$, Kuldeep Dhama ${ }^{7}$ \\ ${ }^{1}$ Department of Microbiology, Punjab Agricultural University, Ludhiana, India. \\ ${ }^{2}$ The Trafford Group of Colleges, Manchester-WA14 5PQ, United Kingdom. \\ ${ }^{3}$ Department of Veterinary Microbiology, Guru Angad Dev Veterinary and Animal Sciences University, Ludhiana, India. \\ ${ }^{4}$ Division of Surgery, ICAR-Indian Veterinary Research Institute, Bareilly, India. \\ ${ }^{5}$ Department of Veterinary Microbiology and Immunology, College of Veterinary Sciences, Uttar Pradesh Pandit Deen Dayal Upadhyaya Pashu Chikitsa Vigyan \\ Vishwavidyalaya Evam Go Anusandhan Sansthan DUVASU, Mathura, India. \\ ${ }^{6}$ School of Life Science and Food Engineering, Huaiyin Institute of Technology, Huaian, China. \\ ${ }^{7}$ Division of Pathology, ICAR-Indian Veterinary Research Institute, Bareilly, India.
}

\begin{tabular}{l}
\hline ARTICLE INFO \\
\hline Received on: $21 / 12 / 2020$ \\
Accepted on: $17 / 02 / 2021$ \\
Available online: 05/04/2021 \\
\hline Key words: \\
Withania somnifera, \\
Ashwagandha, \\
COVID-19, SARS-CoV-2, \\
Withanone, Withaferin-A, \\
immunomodulation, therapy.
\end{tabular}

\section{INTRODUCTION}

The coronavirus disease 2019 (COVID-19), caused by the severe acute respiratory syndrome coronavirus 2 (SARSCoV-2), has presently postured a high worldwide health threat and challenges to limit the spread of the pandemic situation posed

\footnotetext{
${ }^{*}$ Corresponding Author

Manish Dhawan, Department of Microbiology, Punjab Agricultural University, Ludhiana, India; Trafford Group of Colleges, ManchesterWA14 5PQ, United Kingdom.E-mail: dhawanmanish501@gmail.com
}

\begin{abstract}
Severe acute respiratory syndrome coronavirus 2 (SARS-CoV-2), the etiological agent of the potentially fatal coronavirus disease 2019 (COVID-19), has currently affected over 87 million people with worldwide deaths nearing 1.9 million. for ameliorating the effects of SARS-CoV-2 infections in humans and treat COVID-19 patients. Several medicinal

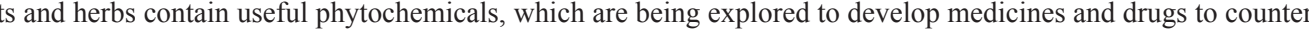
Withania somnifera is a medicinal herb of growing importance that is extensively utilized in Ayurveda. The medicinal attributes of $W$. somnifera are owing to a broad range of bioactive secondary metabolites is one of the most interesting naturally occurring bioactive compounds that possess potent anti-tumorigenic, antiinflammatory, pro-apoptotic, anti-angiogenic, and anti-invasive activities. It might bind to SARS-CoV-2 S protein the functional activities of SARS-CoV-2 main protease (Mpro). Withanolides have been found to control cytokine foring infection and could alleviate the cytokine storm in the lungs. The combined use of withanolides are several other drugs or therapeutic modalities, such as hydroxychloroquine and dexamethasone, has been demonstrated as an efficient strategy to improve the effectiveness of standard chemotherapy or design a robust therapeutic regime and immunomodulatory potentialities of withanolides for alleviating the severity of the disease during SARS-CoV-2 infections. This review highlights the medicinal and therapeutic potential of withanolides against COVID-19.
\end{abstract}

(Boopathi et al., 2020; Dhama et al., 2020a, 2020b). Millions of people have been infected by this virus, while it has killed hundreds of thousands of people across the world (WHO, 2020a). The rapid spread and continuous rising numbers of SARS-CoV-2 cases warrant devising early therapeutic and preventive measures to tackle COVID-19 (Chen et al., 2020; Dhama et al., 2020b; Dhawan et al., 2020; Rabaan et al., 2020; Yatoo et al., 2020). As of today, no effective therapeutic drugs or vaccine candidates are at hand for the COVID-19 treatment, although very high efforts are underway in this direction, and few of these have reached the final stages of clinical investigations (Khan et al., 2020; Rabaan 
et al., 2020; Yatoo et al., 2020). Implementing adequate prevention and control measures, including prompt diagnosis of COVID-19, contact tracing, immediate quarantine, and biosafety measures; and discovering effective vaccines, drugs and therapies could altogether prevent the devastating consequences of this pandemic (Dhama et al., 2020a; Lythgoe and Middleton, 2020). Developing a vaccine against COVID-19 could take insufficient time to be made available that could safeguard the health of millions of people worldwide (WHO, 2020b; Yatoo et al., 2020). Hence, currently available antiviral drugs are being explored against COVID-19 via drug repurposing for identifying new therapeutic use for old and existing drugs that appears to be a prospective approach to cure COVID-19 (Harrison et al., 2020). A mixture of anti-viral drugs, including favipiravir, ritonavir, lopinavir (Khan et al., 2020), and antimalarial drugs (hydroxychloroquine and chloroquine) (Muralidharan et al., 2020), are presently employed as promising therapeutic agents against COVID-19. Apart from these drugs, corticosteroids, like dexamethasone, have proven to be among the most effective drugs in treating COVID-19 (Sharun et al., 2020).

Ayurveda, known as "The Science of Life," an ancient traditional medicinal system that originated and is practiced in India, has been utilized for reducing SARS-CoV-2 infection and treating COVID-19-associated patients (Gautam et al., 2020; Rastogi et al., 2020; Singh et al., 2015). It describes many medicinal plants and herbs possessing a broad range of therapeutic usefulness in curing various kinds of ailments, diseases, and disorders, such as Allium sativum (Garlic), Withania somnifera (W. somnifera) (Ashwagandha), Zingiber officinale Roscoe (Ginger), Tinospora cordifolia (Giloy), Ocimum sanctum (Tulsi), Curcuma longa (Turmeric, Haldi), Glycyrrhiza glabra (Licorice, mulethi), and others (Dhama et al., 2018; Singh et al., 2015, 2017; Tiwari et al., 2018). Hence, researchers are also focusing on exploiting medicines and drugs based on the medicinal, aromatic herbs and plants possessing active phytochemical constituents that could aid in treating COVID-19 patients (Adhikari et al., 2020; Ang et al., 2020; Chen and Nakamura, 2004; Divya et al., 2020; Panyod et al., 2020; Shree et al., 2020). Herbal bioproducts and their derived purified bioactive substances may exhibit anti-SARS-CoV-2 activities by directly impeding the entry or replication of the virus. Remarkably, some natural products are reportedly involved in the blocking of receptor angiotensin-converting enzyme 2 (ACE2) or the Transmembrane protease serine 2-encoded serine protease enzyme, which is needed by coronavirus to induce infection in host cells. Moreover, plant-based products have also shown the inhibiting effects on the life cycle-associated proteins of SARS$\mathrm{CoV}-2$, like chymotrypsin or papain-like proteases (PLpros) (Benarba and Pandiella, 2020; Pandey et al., 2020).

Withania somnifera L. (Solanaceae), popularly recognized as Ashwagandha or Indian ginseng, is used in Ayurveda for vitality, cardio-protective action, and curing several disorders, like respiratory diseases, skin, and neurological disorders (Tetali et al., 2020; Tiwari et al., 2014). Withania somnifera is recognized for its antiviral, anti-inflammatory, immunomodulatory, antioxidant, antimicrobial, anti-diabetic, neuroprotective, analgesic, anti-tumor, anti-aging, anti-arthritic, anti-stress, and immunomodulatory effects (Fugner et al., 1973; Singh et al., 2015, 2017; Tiwari et al., 2018). It is a potent source of various phytochemicals including Withaferin A (WFA), steroidal alkaloids and lactones, and many other chemical compounds (Tiwari et al., 2014; Tong et al., 2011) (Fig. 1). Withania somnifera helps in maintaining sound mental and physical state, body rejuvenation in deteriorated health status, and improves immunity (Singh et al., 2015; Tetali et al., 2020; Tiwari et al., 2018). Phytochemicals of $W$. somnifera have revealed potent antiviral activities against numerous viral infections, such as chikungunya, human papillomavirus (HPV), hemagglutinin type 1 and neuraminidase type 1 , herpes simplex, hepatitis $\mathrm{C}$ virus,
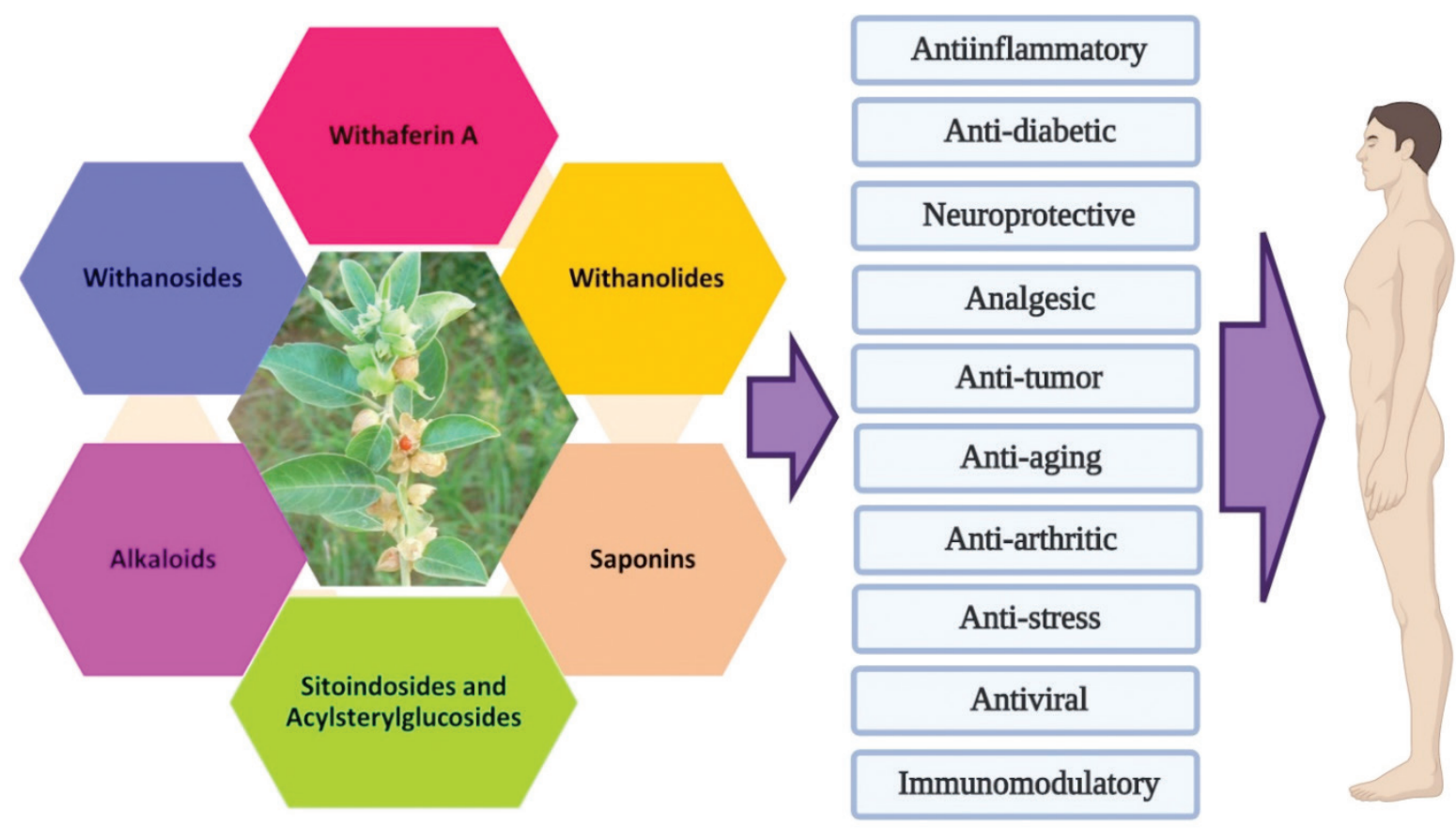

Figure 1. Broad range of phytochemicals and secondary metabolites in Withania somnifera. 
parainfuenza-3, SARS-CoV, and SARS-CoV-2 (Cai et al., 2015; Jain et al., 2018; Kashyap et al., 2020; Kumar et al., 2020a; Leung et al., 2020; Mandlik Ingawale et al., 2020; Straughn and Kakar, 2020; Tandon and Yadav, 2020; Tripathi et al., 2020). Currently, the Indian government, the Indian Medical Research, and the Council of Industrial and Scientific Research have recommended the utilization of $W$. somnifera as a therapy against COVID-19.

Withanolides, the active ingredients of $W$. somnifera, have displayed promising potential to manage COVID-19, and the significant biological action is rendered by Withanolide $\mathrm{D}$, Withaferin-A, Withanoside X, and Withanoside I-VII (Matsuda et al., 2001). Several reports have revealed the potential of withanolides such as WFA, Withanoside $\mathrm{V}$ and $\mathrm{X}$, and withanone (Wi-N) as therapeutic agents for reducing the severity of SARSCoV-2 and usefulness in treating COVID-19 patients (Chikhale et al., 2020; Kumar et al., 2020a; Straughn and Kakar, 2020). The present article focuses on the therapeutic and medicinal potentialities of $W$. somnifera and its phytoconstituents for ameliorating the SARS-CoV-2 severity and usefulness in treating patients with COVID-19.

\section{Methodology for literature review}

Research articles were searched and screened from in different databases such as PubMed, Science Direct, and Google Scholar until October 2020 by using the keywords such as "withanolides and COVID-19"; "medicinal properties and $W$. Somnifera"; therapeutic potential and withanolides"; "Antiviral properties and withanolides"; "W. Somnifera and COVID-19"; "antiviral Properties and $W$. somnifera". The research articles which were published only in the English language were selected.

\section{Inclusion and exclusion criteria}

Research articles were screened and selected independently by authors based on the inclusion and exclusion parameters such as relatedness with the present review. The research findings used in the present review are majorly computational, virtual screenings, and in silico evaluations of withanolides from W. somnifera for therapeutic potentials against COVID-19. Clinical studies, including in vivo and in vitro studies, on $W$. somnifera and withanolides against COVID-19 were searched but not available at the time of search to the best of our knowledge. However, the clinical studies including the immunomodulatory effects of $W$. somnifera extracts under other various pathological conditions were considered to illustrate the medicinal and therapeutic potential of $W$. somnifera. The research articles which were selected are published in peer-reviewed, and SCOPUS indexed journals. The related review papers on $W$. somnifera, and withanolides were excluded but selected for any references for supplementary information such as chemical properties, etc. The titles and abstracts of the research articles were screened first, and irrelevant studies were excluded. Furthermore, full research articles were selected based on their relevance with the present review.

\section{Potential of withanolides in treating COVID-19}

The S-protein of SARS-CoV-2 binds to the ACE2 receptors present on the surface of diverse types of human cells, particularly in the lung cells, and gains entry into the host cells (Lan et al., 2020). Coronavirus mostly targets the airway, alveolar and vascular endothelium, and lung macrophages expressing the ACE2 receptor. ACE2 is demonstrated to express at a higher rate in the respiratory alveolar cells, giving the principal entry site for SARS-CoV-2 into the human host (Ge et al., 2013; Gheblawi et al., 2020). Two subunits have been identified in the SARSCoV-2, of which the S1 subunit exhibits a receptor-binding domain (RBD) that binds with receptor ACE2 of the host cell, whereas the S2 subunit coordinates fusion between the host cell and viral membrane (Du et al., 2009). It is unveiled that SARSCoV-2 possesses a 10-times greater ACE2 receptors affinity in comparison to SARS-CoV that is correlated with high severity of COVID-19 (Shang et al., 2020). Clinical and experimental trials are being conducted to assess the utmost effective therapeutic regime for COVID-19; blocking the entry of viral particles into the host cell by interrupting the interactions of S-protein with the host ACE2 receptor is an efficient strategy to cure COVID-19.

Natural compounds, such as withanone, WFA, caffeic acid phenethyl ester, and various other biological active compounds, are able to interact with the host cell receptor (ACE2) of SARS-CoV-2 and its main protease (Mpro) (Aanouz et al., 2020; Bhardwaj et al., 2020; Kumar et al., 2020a). WFA is a steroidal lactone obtained from $W$. somnifera, possessing high anti-inflammatory and anti-tumorigenic potentials. WFA has been found useful in reducing the release of several cytokines, like tumor necrosis factor- $\alpha$ (TNF $\alpha)$, IL-6, IL-8, and IL-18, in ovarian cancer (Straughn and Kakar, 2019). Several reports have suggested that the treatment with WFA can modulate the gravity of cytokine syndrome/storm owing to its anti-inflammatory actions (Kakar et al., 2017). Recent reports suggested that phytochemicals present in Withania somnifera can be utilized to develop effective therapeutic agents against COVID-19 (Kumar et al., 2020b). Molecular docking analysis suggests the possible interactions of WFA with S-protein RBD, thus inhibiting the interactions with host cell receptors (ACE2) (Balkrishna et al., 2020). Virtual screening and in silico molecular docking analysis of $W$. somnifera revealed that its phytoconstituents firmly bind to SARS-CoV-2 S glycoproteins, two main viral proteases, and host ACE2 receptor to put forth significant antiviral activity; the number of oxygen atoms in the withanolide backbone and structural rearrangements play a critical role for effectual binding (Srivastava et al., 2020) (Table 1). WFA also exerts inhibition activities against influenza and HPV viruses (Cai et al., 2015; Latheef et al., 2017). The blocking of the SARS-CoV-2 binding site to ACE2 is a valuable approach to combat COVID-19 (Fig. 2).

Withanone, a well-known steroidal Withanolide, protects the cells from increased pro-inflammatory cytokines levels, like TNF $\alpha$, IL-6, and IL-1 beta (Pandey et al., 2018), which might aid in treating COVID-19. In a recent study, Balkrishna et al. (2020) reported that Withanone significantly decreased the interfaces between ACE2 and RBD on the SARS-CoV-2 S-protein. Recognition of two salt bridges at the interface was found to be destabilized by the incorporation of Withanone in the ACE2-RBD complex. The interruption of electrostatic forces between the ACE2 and RBD blocks virus from entering into the host cells and its subsequent infectivity.

Withanone (Wi-N) is also predicted to interact with the Mpro and shows an inhibitory potential for SARS-CoV-2 protease (Fig. 2). The inhibition or interference of SARS-CoV-2 protease is 
Table 1. Antiviral activities of most active Withanolides as phytochemicals present in Withania somnifera according to computational studies, specifically against SARS-CoV-2.

\begin{tabular}{|c|c|c|c|}
\hline Withanolides & Molecular formula & Antiviral action against SARS-CoV-2 & References \\
\hline WFA & $\mathrm{C}_{28} \mathrm{H}_{38} \mathrm{O}_{6}$ & $\begin{array}{l}\text { Blocks the binding site of SARS-CoV-2 to the host receptor (ACE2), and } \\
\text { Inhibition of SARS-CoV-2 protease (Mpro) }\end{array}$ & $\begin{array}{l}\text { Balkrishna et al. (2020), Kumar et al. (2020a), } \\
\text { Pandit and Latha (2020) }\end{array}$ \\
\hline Withanone & $\mathrm{C}_{28} \mathrm{H}_{38} \mathrm{O}_{6}$ & $\begin{array}{l}\text { Inhibition of 3-chymotrypsinlike protease (3CLpro), i.e., main viral protease, } \\
\text { and Blocking the ACE2 receptors }\end{array}$ & Kumar et al. (2020b), Balkrishna et al. (2020) \\
\hline QGRG & $\mathrm{C}_{33} \mathrm{H}_{40} \mathrm{O}_{21}$ & Inhibition of NSP15 endoribonuclease & Chikhale et al. (2020) \\
\hline \multirow[t]{2}{*}{ Withanoside V } & $\mathrm{C}_{40} \mathrm{H}_{62} \mathrm{O}_{14}$ & Blocks entry of virus by binding with spike (S) glycoprotein. & Shree et al. (2020) \\
\hline & & Inhibition of SARS-CoV-2 protease (Mpro) & Chikhale et al. (2020) \\
\hline Withanoside X & $\mathrm{C}_{40} \mathrm{H}_{62} \mathrm{O}_{15}$ & Blocks the viral entry by binding with spike (S) protein & Chikhale et al. (2020) \\
\hline Withanolide A & $\mathrm{C}_{28} \mathrm{H}_{38} \mathrm{O}_{6}$ & Inhibition of SARS-CoV-2 protease (Mpro) & Pandit and Latha (2020) \\
\hline Withanolide D & $\mathrm{C}_{28} \mathrm{H}_{38} \mathrm{O}_{6}$ & Inhibition of PLpro & Khanal et al. (2020) \\
\hline Withanolide G & $\mathrm{C}_{28} \mathrm{H}_{38} \mathrm{O}_{5}$ & Inhibition of PLpro & Khanal et al. (2020) \\
\hline Withanolide M & $\mathrm{C}_{28} \mathrm{H}_{38} \mathrm{O}_{6}$ & Inhibition of 3CLpro, and binding to spike $(\mathrm{S})$ protein & Khanal et al. (2020) \\
\hline Withanolide Q & $\mathrm{C}_{28} \mathrm{H}_{38} \mathrm{O}_{6}$ & Modulation of various essential SARS-COV-2 proteins & Khanal et al. (2020) \\
\hline
\end{tabular}

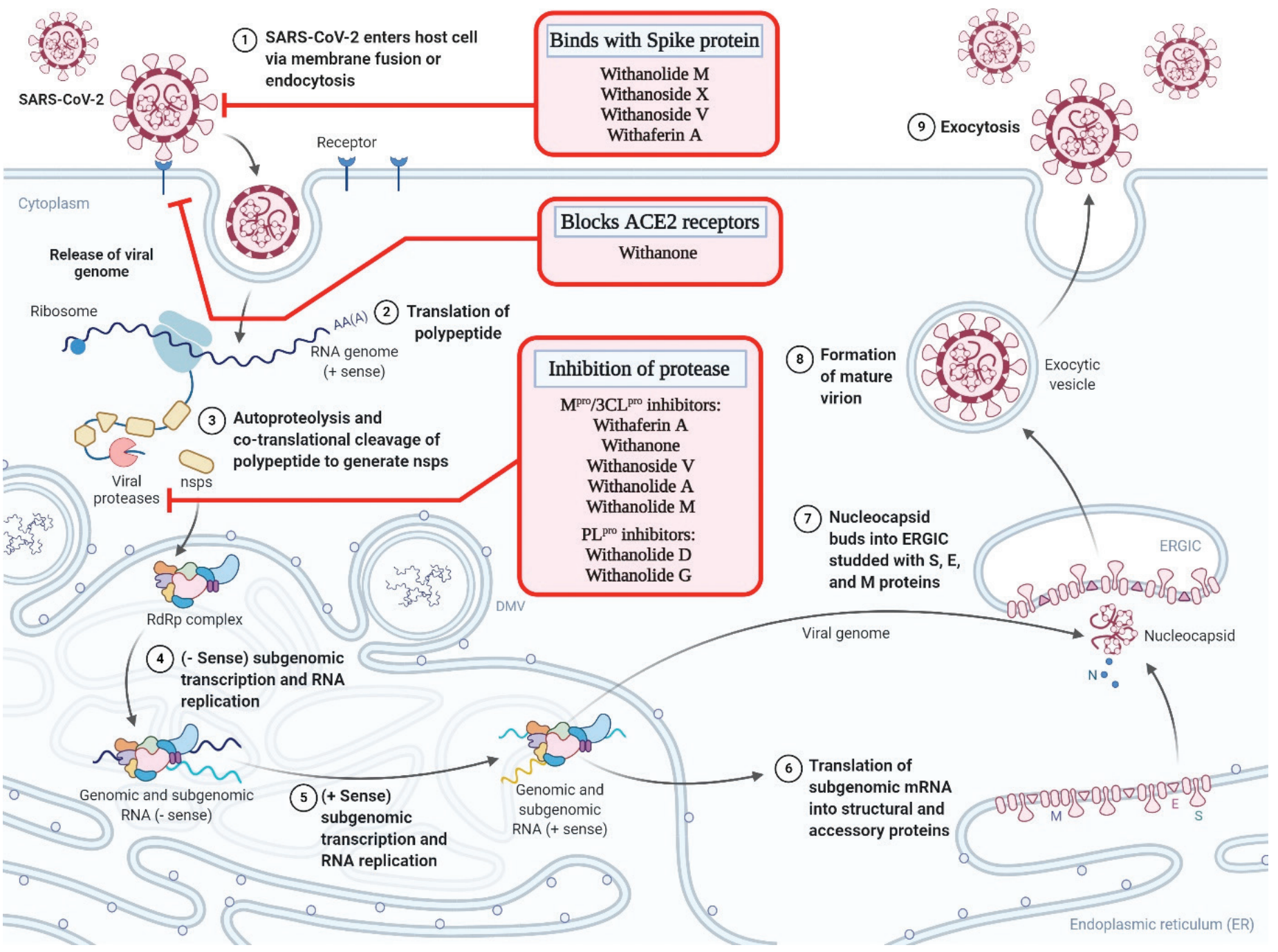

Figure 2. Proposed mechanism of action of Withanolides. Withanolides such as WFA and Withanone (Wi-N) block the process of viral entry by binding with SARSCoV-2 Spike protein; Withanone (Wi-N) and Withanoside V inhibiting the activity of Viral protease and interrupting the cleavage of poly proteins. The image was created with BioRender.com. 
an efficient therapeutic approach for treating COVID-19 (Kumar et al., 2020a, 2020b). A recent docking investigation proposed that four constituents of $W$. somnifera, such as Sitoindoside IX, Withanoside II, Withanoside V, and Withanoside IV, exhibit strong binding affinities with the Mpro, which is also named as 3-chymotrypsin-like protease (3CLpro) of the SARS-CoV-2. Among the four phytoconstituents, Withanoside $\mathrm{V}$ has the highest hydrogen-bonding interactions and binding affinity with the active site of the protein, indicating its active site stability. Hence, Withanoside V can be exploited as a potent inhibitor of Mpro and might provide an effective cure for COVID-19 (Tripathi et al., 2020). In different molecular dynamics simulation and molecular docking studies, among all the selected $W$. Somnifera phytochemicals, Withanoside $\mathrm{V}$ and Somniferine revealed significantly strong interactions with the main viral protease (Mpro). The binding of bioactive phytocompounds with the viral Mpro constrains the process of viral genome replication and transcription by downregulating the cleavage of polyproteins that release non-structural proteins (Shree et al., 2020) (Table 1). The inhibition of the activity of Mpro hinders the replication of the viral genome in the host cell (Zhang et al., 2020).

Chikhale et al. (2020) also reported that Quercetin-3-Ogalactosyl-rhamnosyl-glucoside (QGRG) found in W. somnifera could be a potential Withanolide, as it showed the highest binding affinity with NSP15 endoribonuclease, a crucial and essential protein of the viral machinery. They also reported that Withanoside $\mathrm{X}$, Ashwagandanolide, and Dihydrowithaferin A exhibit strong binding affinities with various essential viral proteins (S-protein). Hence, these phytochemicals can interrupt the essential SARS$\mathrm{CoV}-2$ viral proteins under disease conditions.

A recent computational study revealed that WFA exhibits stronger binding with Mpro compared to the hydroxychloroquine and a plethora of other widely used repurposed drugs for treating COVID-19. Withanolide A also showed significant interactions with Mpro; thus, there is proven evidence of the effectiveness of W. somnifera as a potential medicinal plant for the COVID-19 treatment (Pandit and Latha, 2020) (Table 1). Sudeep et al. (2020) studied the interactive patterns of curcumin, artemisinin, andrographolide, and WFA with the cell receptor "GRP78" exhibiting lower binding energies using molecular docking tools. They also investigated the interaction attributes of these plantoriginated biologically active molecules with Mpro of SARS$\mathrm{CoV}-2$ for gaining deeper understanding and insights. The docking analyses unveiled the highest affinity of WFA with GRP78-SBD target receptor, among the tested compounds. Therefore, it was speculated that WFA inhibits the viral entrance by blocking the receptor. Likewise, among all the other biomolecules, WFA presented superior affinity with the binding site of the protein. This study further corroborated the antiviral properties of medicinal herb-derived WFA against SARS-CoV-2 either by obstructing the host cell's receptor or interfering with the activities of the main viral protease necessary for replication (Grover et al., 2010).

Based on other computational studies, Khanal et al. (2020) found that withanolide-D, G, M, and -Q from $W$. somnifera boost the immune system and inhibit the extent of COVID-19. Withanolide Q modulated the highest numbers of SARS-CoV-2 proteins and revealed the highest drug-likeness score. Moreover,
Withanolide D and $\mathrm{G}$ had a superior binding energy with PLpro (Table 1). Based on the number of hydrogen-bonding interactions and binding energy, it has been analyzed that among a wide range of withanolides, Withanolide M has higher levels of interaction with 3CLpro, and S-protein of SARS-CoV-2 (Khanal et al., 2020). Parida et al. (2020) carried out molecular dynamics simulations for exploring the potential inhibitory activities of phytocompounds against SARS-CoV-2. Among the therapeutic phytochemicals screened from various Indian herbs and plants, 2,3-dihydro WFA and Withanolide $\mathrm{R}$ showed the minimum binding energy for S-protein and Mpro, respectively. The newly explored bioactive chemicals displayed multitherapeutic effectiveness by modulating several biological and cancer pathways.

SARS-CoV-2 infection is associated with cytokine release syndrome and storm, deadly immune reactions, in which the body rapidly releases a vast number of cytokines into the blood. Infection with SARS-CoV-2 caused the build-up of monocytes and macrophages, releasing various cytokines, such as IL-6, IL-1 $\beta$, $\mathrm{TNF}-\alpha$, and IFN- $\gamma$, which trigger adaptive T and B cell immunity for clearing the infection (Huang et al., 2020; Ye et al., 2020). Dysfunctional and violent immune responses resulting in a cytokine release disorder or storm can cause a severe form of pulmonary and lung pathology, leading to excessive inflammation (Tay et al., 2020). Furthermore, the unregulated and excessive cytokine secretions cause myocardial injury and multiorgan dysfunction (Ruan et al., 2020). A current in vitro study on the potential of medicine named "Coronil" containing various withanolides suggested its effectiveness in regulating the cytokine secretions. Coronil attenuated the release of TNF- $\alpha$ and IL- 6 cytokines, and reduced TNF- $\alpha$ triggered nuclear factor-kappaB $(\mathrm{NF}-\kappa \mathrm{B}) /$ activator protein-1 (AP-1) transcriptional activities (Balkrishna et al., 2020). The decrease in cytokine (IL-6, IL-10, and TNF- $\alpha$ ) secretions by withanolides can aid in controlling the cytokine blast during the SARS-CoV-2 infection. Moreover, NF- $\kappa$ B and AP-1 are involved in cytokine secretion and orchestrating lung inflammation (Zhao et al., 2020). Inhibitory action of the withanolides and additional phytoconstituents present in a herbal medicine named Coronil on the NF- $\mathrm{NB} / \mathrm{AP}-1$ pathway indicates a probable contribution of withanolides in interfering with the secretion of cytokines observed during the COVID-19 (Balkrishna et al., 2020).

Hence, withanolides present in $W$. somnifera can be explored as potential biomolecules that interact with SARS$\mathrm{CoV}-2$ and needs additional investigation as drug candidates to treat COVID-19. Until now, withanolides have been studied solely using in silico approaches such as molecular dynamics simulation and docking, which provide a basic understanding of the binding energy as well as the ligands stabilization with viral proteins. The SARS-CoV-2 Mpro is crucial as it plays an important role in stimulating the viral RNA maturation processing into the functional form of proteins, i.e., exoribonuclease, endoribonuclease, and RNA polymerase, which also impair the intrinsic host immunity. Thus, the Mpro might be considered a vital target in designing effective drugs to fight against COVID-19 (Fig. 2) (Shree et al., 2020). In the future, there is an urgent need to evaluate the potential of several phytochemicals present in $W$. somnifera against SARS$\mathrm{CoV}-2$ in amalgamation with other available drug candidates for aiding to formulate a promising cure against COVID-19. 


\section{Clinical studies suggesting the therapeutic potential of $W$. somnifera}

Malik et al. (2007) reported a significant increase in the immune response of Bagg Albino/c mice which were administrated with root extracts of $W$. somnifera. The screening of lymphocyte's ( $\mathrm{T}$ and $\mathrm{B}$ cells) markers showed the prominent enhancement in proliferation and differentiation of a pool of various lymphocytes and their cytokines. They found a significant increase in the expression of T helper (Th1) cells-related cytokines, whereas they found a steep decline in Th2 cells related cytokine IL-4. However, they also reported withanolide-A as a major phytoconstituent in the alcoholic root extract of $W$. somnifera which is responsible for the enhanced response of the Th1 cells.

Teixeira et al. (2006) reported the use of $W$. somnifera extracts as a prophylactic measure to treat Listeria monocytogenes infection. They reported enhanced proliferation of immunologically important cells such as lymphocytes as a result of $W$. somnifera. Furthermore, the enhanced production of interferon-gamma due to $W$. somnifera modulates the immune response which provides protection against intracellular bacterial infection.

In another study, leaf and root extracts of $W$. somnifera have been found to possess anticancerous properties and the potential to enhance the Th1-mediated immune response. They found an enhanced proliferation of T lymphocytes (CD4+/CD8+) and Natural Killer cells along with an increased proliferation of a pool of various other immunologically important cells. The studies suggested the usefulness of $W$. somnifera to modulate the immune response during intracellular infections such as viral infections (Malik et al., 2009).

A recent randomized and double-blind placebo control study on 60 pulmonary TB patients proposed $W$. somnifera root extract's usefulness as an adjuvant in the administration of antibiotics in TB patients. The root extract of $W$. somnifera was reported as an effective adjuvant for antibiotics delivery and recorded a significant increase in T lymphocytes (CD4 and CD8) count compared to control groups. Withania somnifera extracts as an adjuvant combined with anti-TB drugs used in pulmonary TB patients exhibited a positive impact on symptoms and immunological parameters in patients with pulmonary $\mathrm{TB}$ conditions and can be used as effective adjuvants with antiviral drugs (Kumar et al., 2018).

In contrast to this, a current immunological study on HIV patients treated with root extracts of $W$. somnifera showed a significant reduction of CD38 expressing cytotoxic $\mathrm{T}$ lymphocytes (CD8+ T cells). They further suggested that the immune response may differ significantly during different clinical conditions of HIV patients. The reason behind the reduction in immune response was difficult to predict, which varied among the populations. Therefore, there is an urgent need for extensive study covering the impact of withanolides on the immunologically important cellular response (i.e., CD4+ and CD8+ cells) in a large group of patients with viral infections (Maurya et al., 2019).

\section{CONCLUSION AND FUTURE PROSPECTS}

SARS-CoV-2 has constituted high global health emergencies as a devastating pandemic. There is an urgent need to develop promising and successful targeting strategies to counter COVID-19. Apart from chemical and allopathic drugs, naturally available phytoconstituents provide a valuable and rich source of chemical moieties possessing potent antiviral properties. Withania somnifera is well known for the potential of its phytochemicals such as withanolides in treating several ailments and diseases, including viral infections. Withanolides, such as WFA, inhibit the ACE2 receptormediated entry of SARS-CoV-2 into the host cells, and Withanone, Withanolide A, and Withanosides inhibit the Mpro of SARS-CoV-2. Targeting the ACE2 entry receptor and the Mpro is an efficient strategy to inhibit virus replication and spread in the body. Antiinflammatory and immunomodulatory properties of withanolides are needed to explore to their utmost potential to alleviate the pathology of the disease during SARS-CoV-2 infections. Withanolides can be combined with drugs, such as hydroxychloroquine and dexamethasone, which could aid in designing a robust therapeutic strategy for COVID-19 treatment. Phytoconstituents of $W$. somnifera are considered safe, and no harmful effects of their long-term use have been reported. Further explorative research is required for in vivo and in vitro assessment of each Withanolide individually as well as in groups/combination to scrutinize the therapeutic levels of these phytoconstituents against COVID-19.

\section{AUTHOR CONTRIBUTIONS}

All the authors substantially contributed to the conception, compilation of data, checking, and approving the final version of the manuscript, and agreed to be accountable for its contents.

\section{ACKNOWLEDGMENTS}

All the authors acknowledge and thank their respective Institutes and Universities.

\section{CONFLICT OF INTEREST}

All authors declare that there exist no commercial or financial relationships that could, in any way, lead to a potential conflict of interest.

\section{FUNDING}

This compilation is a review article written by its authors and required no substantial funding to be stated.

\section{PUBLISHER'S NOTE}

This journal remains neutral with regard to jurisdictional claims in published institutional affiliation.

\section{REFERENCES}

Aanouz I, Belhassan A, El-Khatabi K, Lakhlifi T, El-Ldrissi M, Bouachrine M. Moroccan medicinal plants as inhibitors against SARSCoV-2 main protease: Computational investigations. J Biomol Struct Dyn, 2020; 1-9; doi:10.1080/07391102.2020.1758790

Adhikari B, Marasini BP, Rayamajhee B, Bhattarai BR, Lamichhane G, Khadayat K, Adhikari A, Khanal S, Parajuli N. Potential roles of medicinal plants for the treatment of viral diseases focusing on COVID-19: a review. Phytother Res, 2020; doi:10.1002/ptr.6893

Ang L, Lee HW, Kim A, Lee MS. Herbal medicine for the management of COVID-19 during the medical observation period: a review of guidelines. Integr Med Res, 2020; 9(3):100465.

Balkrishna A, Pokhrel S, Singh J, Varshney A. Withanone from Withania somnifera may inhibit novel coronavirus (COVID-19) entry by disrupting interactions between viral S-protein receptor binding domain and host ACE2 receptor. Vir J, 2020; doi:10.21203/rs.3.rs-17806/v1

Benarba B, Pandiella A. Medicinal plants as sources of active molecules against COVID-19. Front Pharmacol, 2020; 11:1189; https://doi. org/11:1189. 10.3389/fphar.2020.01189 
Bhardwaj VK, Singh R, Sharma J, Rajendran V, Purohit R, Kumar S. Identification of bioactive molecules from Tea plant as SARSCoV-2 main protease inhibitors. J Biomol Struct Dyn, 2020; 1-10; doi:10.1080/07391102.2020

Boopathi S, Poma AB, Kolandaivel P. Novel 2019 coronavirus structure, mechanism of action, antiviral drug promises and rule out against its treatment. J Biomol Struct Dyn, 2020; 1-10; doi:10.1080/07391102.20 20.1758788

Cai Z, Zhang G, Tang B, Liu Y, Fu X, Zhang X. Promising antiinfluenza properties of active constituent of Withania somnifera ayurvedic herb in targeting neuraminidase of H1N1 influenza: computational study. Cell Biochem Biophys, 2015; 72(3):727-39.

Chen Z, Nakamura T. Statistical evidence for the usefulness of Chinese medicine in the treatment of SARS. Phytother Res, 2004; 18(7):592-4.

Chen ZM, Fu JF, Shu Q, Chen YH, HuaCZ, LiFB, LinR, TangLF, WangTL, WangW, Ying SW, Wei ZX, Zi HY, Sheng Y, Tian MY, Chen MZ, Yuan YZ. Diagnosis and treatment recommendations for pediatric respiratory infection caused by the 2019 novel coronavirus. World J Pediatr, 2020; 16(3):240-6.

Chikhale RV, Gurav SS, Patil RB, Sinha SK, Prasad SK, Shakya A, Shrivastava SK, Gurav NS, Prasad RS. Sars-cov-2 host entry and replication inhibitors from Indian ginseng: an in-silico approach. J Biomol Struct Dyn. 2020; 1-12; doi:10.1080/07391102.2020.1778539

Dhama K, Karthik K, Khandia R, Munjal A, Tiwari R, Rana R, Khurana SK, Sana Ullah, Khan RU, Alagawany M, Farag MR, Dadar M, Joshi SK. Medicinal and therapeutic potential of herbs and plant metabolites / extracts countering viral pathogens - current knowledge and future prospects. Curr Drug Metab, 2018; 19(3):236-63

Dhama K, Khan S, Tiwari R, Sircar S, Bhat S, Malik YS, Singh KP, Chaicumpa W, Bonilla-Aldana DK, Rodriguez-Morales AJ. Coronavirus disease 2019-COVID-19. Clin Microbiol Rev, 2020a; 33(4):e00028-20.

Dhama K, Patel SK, Pathak M, Yatoo MI, Tiwari R, Malik YS, Singh R, Sah R, Rabaan AA, Bonilla ADK, Rodriguez MAJ. An update on SARS-COV-2/COVID-19 with particular reference to its clinical pathology, pathogenesis, immunopathology and mitigation strategies. Travel Med Infect Dis, 2020b; 37(2020): 101755.

Dhawan M, Angural S, Parmar M. Tuberculosis during the COVID-19: Impact, challenges and management. J Exp Biol Agric Sci, 2020; 8(Spl-1):79-86.

Divya M, Vijayakumar S, Chen J, Vaseeharan B, Durán-Lara EF. A review of South Indian medicinal plant has the ability to combat against deadly viruses along with COVID-19? - A review. Microb Pathog, 2020; 148:104277; doi:10.1016/j.micpath.2020.104277

Du L, He Y, Zhou Y, Liu S, Zheng BJ, Jiang S. The spike protein of SARS-CoV - a target for vaccine and therapeutic development. Nat Rev Microbiol, 2009; 7(3):226-36.

Dutta R, Khalil R, Green R, Mohapatra SS, Mohapatra S. Withania somnifera (Ashwagandha) and Withaferin A: potential in integrative oncology. Int J Mol Sci, 2019; 20(21):5310.

Fugner A. Inhibition of immunologically induced inflammation by plant steroid WITHAFERIN-a. Arzneimittel-Forschung, 1973; 23(7): 932-5.

Gautam S, Gautam A, Chhetri S, Bhattarai U. Immunity against COVID-19: potential role of Ayush Kwath. J Ayurveda Integr Med, 2020; doi:10.1016/j.jaim.2020.08.003

Ge XY, Li JL, Yang XL, Chmura AA, Zhu G, Epstein JH, Mazet JK, Hu B, Zhang W, Peng C, Zhang YJ, Luo CM, Tan B, Wang N, Zhu Y, Crameri G, Zhang SY, Wang LF, Daszak P, Shi ZL. Isolation and characterization of a bat SARS-like coronavirus that uses the ACE2 receptor. Nature, 2013; 503(7477):535-8.

Gheblawi M, Wang K, Viveiros A, Nguyen Q, Zhong JC, Turner AJ, Raizada MK, Grant MB, Oudit GY. Angiotensin-converting enzyme 2: SARS-CoV-2 receptor and regulator of the renin-angiotensin system: celebrating the 20th anniversary of the discovery of ACE2. Circ Res, 2020; 126(10):1456-74
Grover A, Shandilya A, Punetha A, Bisaria VS, Sundar D Inhibition of the NEMO/IKK $\beta$ association complex formation, a novel mechanism associated with the NF- $\mathrm{KB}$ activation suppression by Withania somnifera's key metabolite withaferin A. BMC Genomics, 2010;11(Suppl 4):S25; https://doi.org/:10.1186/1471-2164-11-S4-S25

Harrison C. Coronavirus puts drug repurposing on the fast track. Nat Biotechnol, 2020; 38(4):379-81.

Huang C, Wang Y, Li X, Ren L, Zhao J, Hu Y, Zhang L, Fan G, Xu J, Gu X, Cheng Z, Yu T, Xia J, Wei Y, Wu W, Xie X, Wen Yin, Li H, Liu M, Xiao Y, Gao H, Guo L, Xie J, Wang G, Jiang R, Gao Z, Jin Q, Wang J, Cao B. Clinical features of patients infected with 2019 novel coronavirus in Wuhan, China. Lancet, 2020; 395(10223):497-506.

Jain J, Narayanan V, Chaturvedi S, Pai S, Sunil S. In vivo evaluation of Withania somnifera-based Indian traditional formulation (amukkara choornam), against chikungunya virus-induced morbidity and arthralgia. J Evid Based Integr Med, 2018; 23:1-7.

Kakar SS, Parte S, Carter K, Joshua IG, Worth C, Rameshwar P, Ratajczak MZ. Withaferin a (WFA) inhibits tumor growth and metastasis by targeting ovarian cancer stem cells. Oncotarget, 2017; 8(43):74494-505.

Kashyap VK, Dhasmana A, Yallapu MM, Chauhan SC, Jaggi M. Withania somnifera as a potential future drug molecule for COVID-19. 2020; 2(4):FDD50; https://doi.org/10.4155/fdd-2020-0024

Khan Z, Karatas Y, Rahman H. Anti-COVID-19 drugs: need for more clinical evidence and global action. Adv Ther, 2020; 37(6):2575-79.

Khanal P, Patil BM, Pasha I, Dey YN, Chand S. Withanolides from Withania somnifera as an immune booster and their therapeutic option against COVID-19. Res Sq, 2020; doi:10.21203/rs.3.rs-32955/v1

Kumar D, Kumari K, Jayaraj A, Kumar V, Kumar RV, Dass SK, Chandra R, Singh P. Understanding the binding affinity of noscapines with protease of SARS-CoV-2 for COVID-19 using MD simulations at different temperatures. J Biomol Struc Dyn, 2020b; 1-14; doi:10.1080/07391102.2 020.1752310

Kumar R, Rai J, Kajal NC, Devi P. Comparative study of effect of Withania somnifera as an adjuvant to DOTS in patients of newly diagnosed sputum smear positive pulmonary tuberculosis. Indian J Tuberc, 2018; 65(3):246-51.

Kumar V, Dhanjal JK, Kaul SC, Wadhwa R, Sundar D Withanone and caffeic acid phenethyl ester are predicted to interact with main protease (Mpro) of SARS-CoV-2 and inhibit its activity. J Biomol Struct Dyn, 2020a; 1-13; doi:10.1080/07391102.2020.1772108

Lan J, Ge J, Yu, J, Shan, S, Zhou H, Fan S, Zhang Q, Shi X, Wang Q, Zhang L, Wang X. Structure of the SARS-CoV-2 spike receptor-binding domain bound to the ACE2 receptor. Nature. 2020; 581(7807):215-20.

Latheef SK, Dhama K, Samad HA, Wani MY, Kumar MA, Palanivelu M, Malik YS, Singh SD, Singh R. Immunomodulatory and prophylactic efficacy of herbal extracts against experimentally induced chicken infectious anaemia in chicks: assessing the viral load and cell mediated immunity. Virusdisease, 2017; 28(1):115-20.

Leung JM, Yang CX, Sin DD. COVID-19 and nicotine as a mediator of ACE-2. Eur Respir J, 2020; 55(6), 2001261; doi:10.1183/13993003.01261-2020

Lythgoe MP, Middleton P. Ongoing clinical trials for the management of the COVID- 19 pandemic. Trends Pharmacol Sci, 2020; 41(6):363-82.

Malik F, Kumar A, Bhushan S, Mondhe DM, Pal HC, Sharma R, Khajuria A, Singh S, Singh G, Saxena AK, Suri KA, Qazi GN, Singh J. Immune modulation and apoptosis induction: two sides of antitumoural activity of a standardised herbal formulation of Withania somnifera. Eur J Cancer, 2009; 45:1494-509.

Malik F, Singh J, Khajuria A, Suri KA, Satti NK, Singh S, Kaul MK, Kumar A, Bhatia A, Qazi GN. A standardized root extract of Withania somnifera and its major constituent withanolide-A elicit humoral and cellmediated immune responses by up regulation of Th1-dominant polarization in BALB/c mice. Life Sci, 2007; 80:1525-38.

Mandlik Ingawale DS, Namdeo AG. Pharmacological evaluation of Ashwagandha highlighting its healthcare claims, safety, and 
toxicity aspects. J Diet Suppl, 2020; 1-44; doi:10.1080/19390211.2020.1 741484

Matsuda H, Murakami T, Kishi A, Yoshikawa M. Structures of withanosides I, II, III, IV, V, VI, and VII, new withanolide glycosides, from the roots of Indian Withania somnifera Dunal. and inhibitory activity for tachyphylaxis to clonidine in isolated guinea-pig ileum. Bioorg Med Chem, 2001; 9(6):1499-507.

Maurya SP, Das BK, Singh R, Tyagi S. Effect of Withania somnifera on CD38 expression on CD8+ T lymphocytes among patients of HIV infection. Clin Immunol, 2019; 203:122-4.

Muralidharan N, Sakthivel R, Velmurugan D, Gromiha MM. Computational studies of drug repurposing and synergism of lopinavir, oseltamivir and ritonavir binding with SARS-CoV-2 protease against COVID-19. J Biomol Struct Dyn, 2020; 1-6; doi:1080/07391102.2020.1752802

Pandey A, Bani S, Dutt P, Kumar Satti N, Avtar Suri K, Nabi Qazi G. Multifunctional neuroprotective effect of Withanone, a compound from Withania somnifera roots in alleviating cognitive dysfunction. Cytokine, 2018; 102:211-21.

Pandey A, Khan MK, Hamurcu M, Gezgin S. Natural plant products: a less focused aspect for the COVID-19 viral outbreak. Front Plant Sci, 2020; 11:568890; https://doi.org/:10.3389/fpls.2020.568890

Pandit M, Latha N. In silico studies reveal potential antiviral activity of phytochemicals from medicinal plants for the treatment of COVID-19 infection. Res Sq, 2020.

Panyod S, Ho CT, Sheen LY. Dietary therapy and herbal medicine for COVID-19 prevention: a review and perspective. J Tradit Complement Med, 2020; 10(4):420-7.

Parida, PK, Paul D, Chakravorty D. The natural way forward: molecular dynamics simulation analysis of phytochemicals from Indian medicinal plants as potential inhibitors of SARS-CoV-2 targets. Phytother Res, 2020; 34(12):3420-33; https://doi.org/:10.1002/ptr.6868

Rabaan AA, Al-Ahmed SH, Sah R, Tiwari R, Yatoo MI, Patel SK, Pathak M, Malik YS, Dhama K, Singh KP, Bonilla-Aldana DK, Haque S, Martinez-Pulgarin DF, Rodriguez-Morales AJ, Leblebicioglu H. SARSCoV-2/COVID-19 and advances in developing potential therapeutics and vaccines to counter this emerging pandemic. Ann Clin Microbiol Antimicrob, 2020; 19(1):40.

Rastogi S, Pandey DN, Singh RH. COVID-19 pandemic: a pragmatic plan for ayurveda intervention. J Ayurveds Integr Med, 2020; doi:10.1016/j.jaim.2020.04.002

Ruan Q, Yang K, Wang W, Jiang L, Song J. Clinical predictors of mortality due to COVID-19 based on an analysis of data of 150 patients from Wuhan, China. Intensive Care Med, 2020; 46(5):846-8.

Shang J, Ye G, Shi K, Wan Y, Luo C, Aihara H, Geng Q, Auerbach A, Li Fang. Structural basis of receptor recognition by SARSCoV-2. Nat, 2020; 581:221-4.

Sharun K, Tiwari R, Dhama J, Dhama K. Dexamethasone to combat cytokine storm in COVID-19: clinical trials and preliminary evidence. Int J Surg, 2020; 4(82):179-81.

Shree P, Mishra P, Selvaraj C, Singh SK, Chaube R, Garg N, Tripathi YB. Targeting COVID-19 (SARS-CoV-2) main protease through active phytochemicals of ayurvedic medicinal plants -Withania somnifera (Ashwagandha), Tinospora cordifolia (Giloy) and Ocimum sanctum (Tulsi) - a molecular docking study. J Biomol Struct Dyn, 2020; 1-14; doi:10.108 0/07391102.2020.1810778

Singh P, Guleri R, Angurala A, Kaur V, Kaur K, Kaul SC, Wadhwa R, Pati PK. Addressing challenges to enhance the bioactives of Withania somnifera through organ, tissue, and cell culture based approaches. BioMed Res Int, 2017; 2017(3278494):1-15.

Singh P, Guleri R, Singh V, Kaur G, Kataria H, Singh B, Kaur G, Kaul SC, Wadhwa R, Pati P K. Biotechnological interventions in Withania somnifera (L.) dunal. Biotechnol Genetic Eng Rev, 2015; 31(1-2):1-20.

Srivastava A, Siddiqui S, Ahmad R, Mehrotra S, Ahmad B, Srivastava AN. Exploring nature's bounty: identification of Withania somnifera as a promising source of therapeutic agents against COVID-19 by virtual screening and in silico evaluation. J Biomol Struct Dyn. 2020; 27:1-51; doi:10.1080/07391102.2020.1835725
Straughn AR, Kakar SS. Withaferin a ameliorates ovarian cancer-induced cachexia and proinflammatory signalling. J Ovarian Res, 2019; 12(1):115.

Straughn AR, Kakar SS. Withaferin A: a potential therapeutic agent against COVID-19 infection. J Ovarian Res, 2020; 13(1):79.

Sudeep HV, Gouthamchandra K, Shyamprasad K. Molecular docking analysis of Withaferin A from Withania somnifera with the Glucose regulated protein 78 (GRP78) receptor and the SARS-CoV-2 main protease. Bioinformation, 2020; 16(5):411-7; doi:10.6026/97320630016411

Tandon N, Yadav SS. Safety and clinical effectiveness of Withania Somnifera (Linn.) dunal root in human ailments. J Ethnopharmacol, 2020; 255:112768.

Tay MZ, Poh, CM, Rénia L, Macary PA, Ng LFP. The trinity of COVID-19: immunity, inflammation and intervention. Nat Rev Immunol, 2020; 20(6):363-74.

Teixeira ST, Valadares MC, Gonçalves SA, de Melo A, Queiroz ML. Prophylactic administration of Withania somnifera extract increases host resistance in Listeria monocytogenes infected mice. Int Immunopharmacol, 2006; 6(10):1535-42; doi:10.1016/j.intimp.2006.03.016

Tetali SD, Acharya S, Ankari AB, Nanakram V, Raghavendra AS Metabolomics of Withania somnifera (L.) dunal: advances and applications. J Ethnopharmacol, 2020; doi:10.1016/j.jep.2020.113469.

Tiwari R, Chakraborty S, Saminathan M, Dhama K, Singh SV. Ashwagandha (Withania somnifera): role in safeguarding health, immunomodulatory effects, combating infections and therapeutic applications: a review. J Biol Sci, 2014; 14(2):77-94.

Tiwari R, Latheef SK, Ahmed I, Iqbal HMN, Bule MH, Dhama K, Samad HA, Karthik K, Alagawany M, El-Hack MEA, Yatoo MI, Farag MR. Herbal Immunomodulators - a remedial panacea for designing and developing effective drugs and medicines: current scenario and future prospects. Curr Drug Metab, 2018; 19(3):264-301.

Tong X, Zhang H, Timmerman BN. Chlorinated withanolides from Withania somnifera. Phytochem Lett, 2011; 4(4):411-4.

Tripathi MK, Singh P, Sharma S, Singh TP, Ethayathulla AS, Kaur P. Identification of bioactive molecule from Withania somnifera (Ashwagandha) as SARS-CoV-2 main protease inhibitor. J Biomol Struct Dyn, 2020; 1-14; doi:10.1080/07391102.2020.1790425.

WHO. Coronavirus disease (COVID-19) dashboard. WHO, Geneva, Switzerland, 2020a. Available via https://covid19.who.int (Accessed 7 December 2020).

WHO. Draft landscape of COVID-19 candidate vaccines. WHO, Geneva, Switzerland, 2020b. Available via https://www.who.int/ publications $/ \mathrm{m} /$ item $/$ draft-landscape-of-covid-19-candidate-vaccines (Accessed 7 December 2020).

Yatoo MI, Hamid Z, Parray OR, Wani AH, U1 HA, Saxena A, Patel SK, Pathak M, Tiwari R, Malik YS, Sah R, Rabaan AA, Rodriguez Morales AJ, Dhama K. COVID-19 - Recent advancements in identifying novel vaccine candidates and current status of upcoming SARS-CoV-2 vaccines. Hum Vaccin Immunother, 2020; 16(12):2891-904

Ye Q, Wang B, Mao J. The pathogenesis and treatment of the cytokine Storm' in COVID-19. J Inf Secur, 2020; 80(6):607-13.

Zhang L, Lin D, Sun X, Curth U, Drosten C, Sauerhering L, Becker S, Rox K, Hilgenfeld R. Crystal structure of SARS-CoV-2 main protease provides a basis for design of improved $\alpha$-ketoamide inhibitors. Science, 2020; 368(6489):409-12.

Zhao Q, Meng M, Kumar R, Wu Y, Huang J, Deng Y, Weng Z, Yang L. Lymphopenia is associated with severe coronavirus disease 2019 (COVID-19) infections: a systemic review and meta-analysis. Int J Infect Dis, 2020; 96:131-5.

How to cite this article:

Dhawan M, Parmar M, Sharun K, Tiwari R, Bilal M, Dhama K. Medicinal and therapeutic potential of withanolides from Withania somnifera against COVID-19. J Appl Pharm Sci, 2021; 11(04):006-013. 